\title{
Rapid Screening and Identification of Antitumor Ingredients from the Mangrove Endophytic Fungus Using an Enzyme-Immobilized Magnetic Nanoparticulate System
}

\author{
Nan Wei ${ }^{1}$, Jun Zhao ${ }^{1}$, Guimei Wu ${ }^{1}$, Wenjuan Cao ${ }^{1}$, Pei Luo ${ }^{2}$, Zhifeng Zhang ${ }^{2}$, Gang Chen ${ }^{3,4,5, *}$ and Lu Wen ${ }^{1, *}$ \\ 1 School of Pharmacy, Guangdong Pharmaceutical University, Guangzhou 510006, China; \\ weinan7789@126.com (N.W.); zhao_jun0102@163.com (J.Z.); wgm19090@163.com (G.W.); \\ adaaa890@126.com (W.C.) \\ 2 State Key Laboratory for Quality Research in Chinese Medicine, Macau University of Science and Technology, \\ Macau 000853, China; pluo@must.edu.mo (P.L.); zfzhang@must.edu.mo (Z.Z.) \\ 3 The Center for Drug Research and Development, Guangdong Pharmaceutical University, \\ Guangzhou 510006, China \\ 4 Guangdong Provincial Key Laboratory of Advanced Drug Delivery, Guangdong Pharmaceutical University, \\ Guangzhou 510006, China \\ 5 Guangdong Provincial Engineering Center of Topical Precise Drug Delivery System, \\ Guangdong Pharmaceutical University, Guangzhou 510006, China \\ * Correspondence: cg753@126.com (G.C.); gdpuwen@gdpu.edu.cn (L.W.); Tel.: +86-020-39352117 (G.C.); \\ +86-020-39352141 (L.W.)
}

Citation: Wei, N.; Zhao, J.; Wu, G.; Cao, W.; Luo, P.; Zhang, Z.; Chen, G.; Wen, L. Rapid Screening and Identification of Antitumor Ingredients from the Mangrove Endophytic Fungus Using an Enzyme-Immobilized Magnetic Nanoparticulate System. Molecules 2021, 26, 2255. https://doi.org/ $10.3390 /$ molecules 26082255

Academic Editors: Yi Lu and Yongtai Zhang

Received: 27 February 2021

Accepted: 7 April 2021

Published: 13 April 2021

Publisher's Note: MDPI stays neutral with regard to jurisdictional claims in published maps and institutional affiliations.

Copyright: () 2021 by the authors. Licensee MDPI, Basel, Switzerland. This article is an open access article distributed under the terms and conditions of the Creative Commons Attribution (CC BY) license (https:// creativecommons.org/licenses/by/ $4.0 /)$.

\begin{abstract}
As a consequence of recent progression in biomedicine and nanotechnology, nanoparticlebased systems have evolved as a new method with extensive applications in responsive therapy, multimodal imaging, drug delivery and natural product separation. Meanwhile, the magnetic nanoparticulate system has aroused great interest for separation and purification because of its excellent magnetic properties. Phospholipase $\mathrm{A}_{2}\left(\mathrm{PLA}_{2}\right)$ is a highly expressed regulator to promote the growth of various cancers and is an ideal target to treat cancers. In this study, a novel strategy based on ligand-receptor interactions to discover novel PLA 2 inhibitors was established, in which $\mathrm{PLA}_{2}$-functionalized $\mathrm{Fe}_{3} \mathrm{O}_{4} @ \mathrm{PLGA}-\mathrm{PEG}-\mathrm{NH}_{2}$ magnetic nanoparticles were used as a supporting material combined with high-performance liquid chromatography-mass spectrometry, aiming to accelerate the discovery of novel $\mathrm{PLA}_{2}$ inhibitors from natural sources such as mangrove endophytic fungi. Under the optimized ligand fishing conditions, six target compounds were ultimately fished and identified to be cyclic peptides (1-3) and sterols (4-6), which compounds 1, 2 and 4-6 have well-documented cytotoxicities. Compound 3 exerted better inhibitory effect on A549 cells by experiment. In conclusion, $\mathrm{PLA}_{2}$-functionalized $\mathrm{Fe}_{3} \mathrm{O}_{4} @$ PLGA-PEG- $\mathrm{NH}_{2}$ magnetic nanoparticlesbased ligand fishing provided a feasible, selective and effective platform for the efficient screening and identification of antitumor components from natural products.
\end{abstract}

Keywords: magnetic nanoparticles; ligand fishing; phospholipase $\mathrm{A}_{2}$; endophytic fungus

\section{Introduction}

In recent decades, nanoparticle-based systems have evolved as a new system with extensive applications in multiple biomedical applications, including the diagnosis and therapy of various cancers [1-4]. In the meanwhile, these systems have also been used for separation due to their unique and inherent advantages such as high efficiency of separation and time-saving compared to the conventional bioassay-guided fractionation methods [5,6].

To date, many compounds extracted from natural products have shown considerable antitumor activities [7], although quick extraction and separation of these compounds still remains challenging. This phenomenon has attracted substantial interest in the discovering 
of novel methods to isolate the active ingredients from natural products. Ligand fishing, based on the target-ligand binding, was designed to attach the targets such as enzymes, membrane proteins to the carrier material, has been recognized as a convenient and efficient way to achieve multitarget or multichannel screening of natural products, coupled with chromatography or mass spectrometry (HPLC, MS or HPLC-MS) [8,9]. Moreover, new materials used in ligand fishing such as the magnetic nanoparticulate system further enhanced targets' separation due to their great surface area and convenient separation process [10]. Recently, emerging evidence proved that ligand fishing based on magnetic nanoparticles (MNPs) has been applied to screen antitumor compounds from natural products $[11,12]$.

Phospholipase $\mathrm{A}_{2}\left(\mathrm{PLA}_{2}\right)$ has been recognized as an important drug target for the initiation and progression of certain types of cancers, including liver, lung, prostate, breast cancers and chronic myelocytic leukemia [13-17]. PLA 2 can specifically cut phospholipids at the sn-2 ester bond to release free fatty acids, mainly arachidonic acid (AA) and lysophospholipids (LPLs) [18]. It mediates the growth and proliferation of cancer cells primarily by releasing AA from glycerophospholipids and the corresponding metabolites from the AA. Besides, PLA $_{2}$ may also mediate carcinogenesis by releasing LPLs, which can be metabolized into lysophosphatidic acid (LPA) to promote cell growth [19]. Therefore, $\mathrm{PLA}_{2}$ or inhibition of PLA 2 was regarded as an important target and an effective way to discover drugs against cancers.

Mangrove endophytic fungi, which grow in tropical and subtropical intertidal estuarine zones, are rich in unique and bioactive compounds with potentials as new medicinal agents [20]. Recently, many novel anticancer compounds with unique structures and skeletons have been identified from mangrove fungi [21]. In addition, PLGA is a polymer with certain degree of hydrophobicity to encapsulate $\mathrm{Fe}_{3} \mathrm{O}_{4} \mathrm{MNPs}$ via hydrophobic interaction, which is a Food and Drug Administration (FDA)-approved material and considered safe because of its excellent biodegradability and biocompatibility [22]. Considering the adverse limitations of $\mathrm{Fe}_{3} \mathrm{O}_{4}$ MNPs [23], it is highly desirable to use PLGA-PEG- $\mathrm{NH}_{2}$ copolymer as a linker between $\mathrm{Fe}_{3} \mathrm{O}_{4} \mathrm{MNPs}$ and enzyme. In this study, for the first time, we reported a facile method to screen antitumor compounds from the fungal extracts based on a PLA $\mathrm{A}_{2}$-functionalized $\mathrm{Fe}_{3} \mathrm{O}_{4} @ \mathrm{PLGA}-\mathrm{PEG}-\mathrm{NH}_{2}$ magnetic nanoparticles ( $\mathrm{PLA}_{2}$-MNPs) system in combination with LC-MS technology. Amino-terminated PLGA-PEG was firstly synthesized followed by the preparation of $\mathrm{Fe}_{3} \mathrm{O}_{4} @$ PLGA-PEG- $\mathrm{NH}_{2}$ MNPs with emulsion, evaporation and immobilization of $\mathrm{PLA}_{2}$ on the surface of $\mathrm{Fe}_{3} \mathrm{O}_{4} @$ PLGA-PEG-NH $\mathrm{N}_{2}$ MNPs for ligand fishing. This new strategy was validated by screening antitumor compounds from the crude extract of endophytic fungus Pseudopithomyces sp. 1512101. The antitumor activities of screened compounds were determined by MTT assay. As a result, six compounds were efficiently isolated and identified and fusaristatin $\mathrm{C}(3)$, one of the mentioned compounds, exhibited better inhibitory effect on A549 cells. The study confirmed the suitability of using PLA $\mathrm{PL}_{2}$-MNPs as a tool of ligand fishing to discover antitumor compounds and accelerate the discovery of new drug candidates from natural products.

\section{Results and Discussion}

\subsection{Characterization of $\mathrm{Fe}_{3} \mathrm{O}_{4} @ P L G A-P E G-\mathrm{NH}_{2} \mathrm{MNPS}$}

MNPs have been widely applied in chemical and biological research because of easy surface modifications, excellent stability and convenient solid-liquid separation. At present, most MNPs are based on $\mathrm{Fe}_{2} \mathrm{O}_{3}, \mathrm{Fe}_{3} \mathrm{O}_{4}$ and other iron oxides. However, the surface of MNPs such as $\mathrm{Fe}_{3} \mathrm{O}_{4}$ does not have functional groups to be linked with enzymes or proteins. PLGA-PEG-NH $\mathrm{N}_{2}$, a di-block copolymer often used as a drug carrier, can be easily modified with various chemical groups due to its low toxicity and high biocompatibility. Therefore, in this study, $\mathrm{Fe}_{3} \mathrm{O}_{4}$ MNPs were designed to be encapsulated in the PEG-PLGA-NH carriers to allow magnetic separation and further decoration.

PLGA-PEG-NH $\mathrm{N}_{2}$ was synthesized and covered on the surface of $\mathrm{Fe}_{3} \mathrm{O}_{4}$ MNPs to yield $\mathrm{Fe}_{3} \mathrm{O}_{4} @$ PLGA-PEG-NH $\mathrm{N}_{2}$ MNPs. The interaction between $\mathrm{Fe}_{3} \mathrm{O}_{4} \mathrm{MNP}$ surface and 
PLGA-PEG-NH $\mathrm{N}_{2}$ was mainly based on hydrophobic interaction as both $\mathrm{Fe}_{3} \mathrm{O}_{4}$ MNPs and PLGA were substantially hydrophobic. The $\mathrm{Fe}_{3} \mathrm{O}_{4} \mathrm{MNPs}$ tend to hide inside of the hydrophobic core of the PLGA-PEG- $\mathrm{NH}_{2}$ polymeric aggregates to minimize the entropy in the aqueous dispersion system and, therefore, formed $\mathrm{Fe}_{3} \mathrm{O}_{4} @$ PLGA-PEG- $\mathrm{NH}_{2}$ MNPs. Using DCC/NHS coupling method, activated PLGA-COOH was reacted with excess $\mathrm{NH}_{2}$-PEG$\mathrm{NH}_{2}$ to afford PLGA-PEG-NH $\mathrm{N}_{2}$ copolymer (Figure 1A). The synthesized PLGA-PEG-NH was characterized by FTIR and ${ }^{1} \mathrm{H}$ NMR spectroscopies. FTIR spectrum (Figure 1B) confirmed the conjugation of $\mathrm{NH}_{2}-\mathrm{PEG}-\mathrm{NH}_{2}$ to $\mathrm{PLGA}-\mathrm{COOH}$, as evidenced by the vibration peaks at $1625 \mathrm{~cm}^{-1}$ (amide $\mathrm{C}=\mathrm{O}$ ) and $1578 \mathrm{~cm}^{-1}$ (NH bond) which were not shown in the spectrum of PLGA-COOH or $\mathrm{NH}_{2}-\mathrm{PEG}-\mathrm{NH}_{2}$. The successful conjugation of PLGA-COOH and $\mathrm{NH}_{2}$-PEG- $\mathrm{NH}_{2}$ was confirmed by the ${ }^{1} \mathrm{H}$ NMR spectroscopy (Figure 1C). The peaks at $1.54,5.18$, and $4.79 \mathrm{ppm}$ were assigned to the $\mathrm{CH}_{3}, \mathrm{CH}_{2}$ and $\mathrm{CH}$ protons of PLGA, respectively, and that at $3.60 \mathrm{ppm}$ corresponded to the $\mathrm{CH}_{2}$ proton of $\mathrm{NH}_{2}-\mathrm{PEG}-\mathrm{NH}_{2}$ blocks. Figure $\mathrm{S} 1$ shows the FTIR spectra of $\mathrm{Fe}_{3} \mathrm{O}_{4}$ MNPs, PLGA-PEG- $\mathrm{NH}_{2}$ and $\mathrm{Fe}_{3} \mathrm{O}_{4} @$ PLGAPEG-NH $\mathrm{H}_{2}$ MNPs. The spectrum of uncoated $\mathrm{Fe}_{3} \mathrm{O}_{4}$ MNPs exhibited the vibration peaks of typical functional groups at $550-650 \mathrm{~cm}^{-1}$, which were absent from the spectrum of PLGA-PEG- $\mathrm{NH}_{2}$ or $\mathrm{Fe}_{3} \mathrm{O}_{4} @$ @LGA-PEG-NH $\mathrm{N}_{2}$ MNPs, indicating that $\mathrm{Fe}_{3} \mathrm{O}_{4}$ MNPs had been successfully loaded into the matrix of PLGA-PEG-NH $\mathrm{N}_{2}$ di-block copolymers.

A

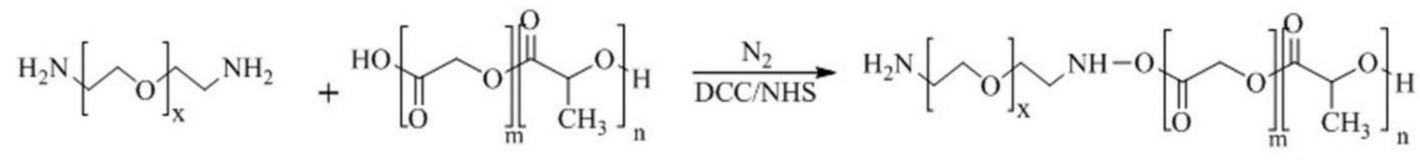

PEG bis(amine)

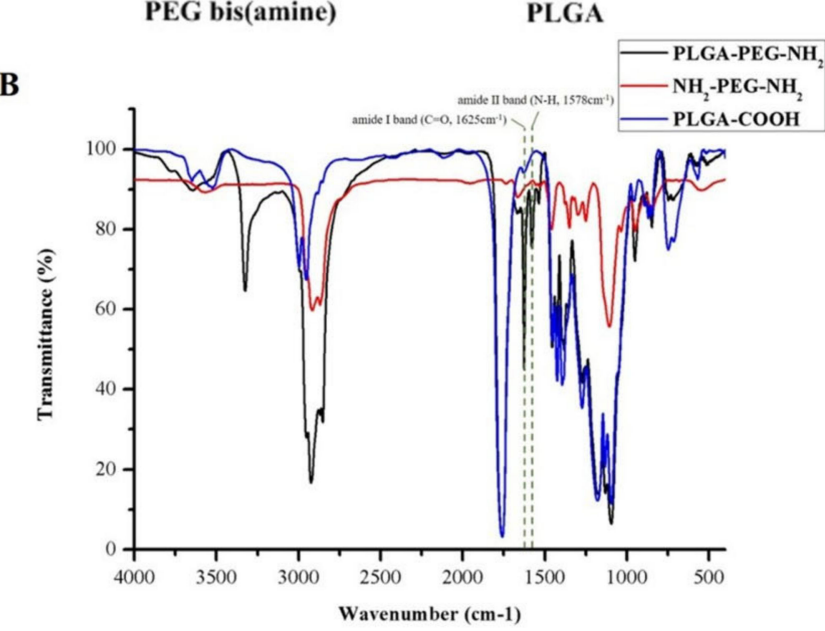

PLGA-PEG-NH

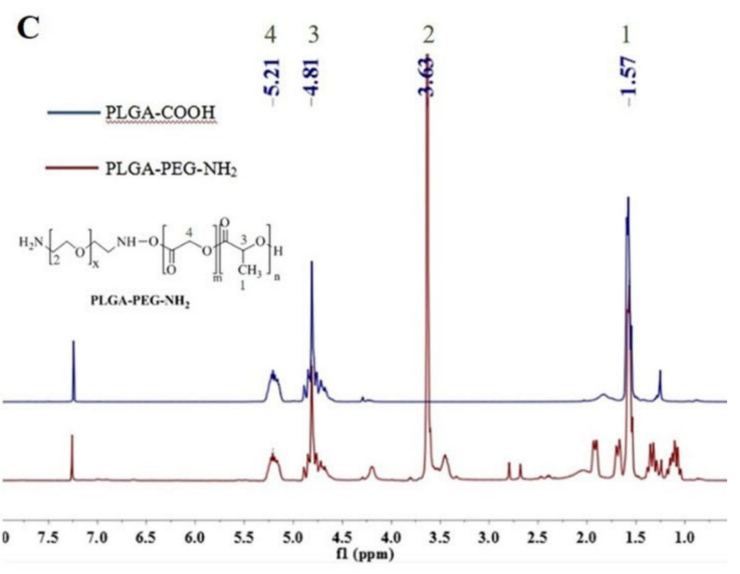

Figure 1. Characterizations of synthesized copolymers by ${ }^{1} \mathrm{H}$ NMR and FTIR spectroscopies. (A) Synthesis scheme; (B) FTIR spectra of PLGA-COOH, $\mathrm{NH}_{2}-\mathrm{PEG}-\mathrm{NH}_{2}$ and PLGA-PEG-NH ${ }_{2} ;(\mathrm{C}){ }^{1} \mathrm{H}$ NMR spectra of PLGA-COOH and PLGA-PEG-NH 2 .

\subsection{Optimization of Preparation Conditions for $\mathrm{Fe}_{3} \mathrm{O}_{4} @ P L G A-P E G-\mathrm{NH}_{2} \mathrm{MNPs}$}

To optimize the preparation conditions for MNPs, the amount of $\mathrm{Fe}_{3} \mathrm{O}_{4} \mathrm{MNPs}$, the volume of dichloromethane and effects of preparation methods were systematically investigated.

$\mathrm{Fe}_{3} \mathrm{O}_{4} @$ PLGA-PEG-NH $\mathrm{N}_{2}$ MNPs were prepared by single-emulsion $(\mathrm{o} / \mathrm{w})$ and multipleemulsion (w/o/w) methods. As shown in Figure S2A (in the Supplementary Materials), when the magnetic field strength reached 3000 Oe, the saturated magnetization of the MNPs prepared by the single-emulsion method $(0.32 \mathrm{emu} / \mathrm{g})$ was 2.6 -fold to that prepared by the multiple-emulsion method $(0.12 \mathrm{emu} / \mathrm{g})$. Thus, the MNPs prepared by the single-emulsion method showed better magnetic properties.

Moreover, the effects of the amount of $\mathrm{Fe}_{3} \mathrm{O}_{4}$ MNPs on the particle size, PDI and saturated magnetization of MNPs were also investigated. As the amount of $\mathrm{Fe}_{3} \mathrm{O}_{4} \mathrm{MNPs}$ increased, the PDI of $\mathrm{Fe}_{3} \mathrm{O}_{4} @$ PLGA-PEG-NH $\mathrm{N}_{2}$ MNPs remained mostly unchanged while the particle size slightly increased (Figure S2B and Figure S2C). Figure S2D shows the 
saturated magnetization of MNPs with different $\mathrm{Fe}_{3} \mathrm{O}_{4}$ contents: $1000 \mathrm{mg}$ (I), $800 \mathrm{mg}$ (II), $600 \mathrm{mg}$ (III), $400 \mathrm{mg}$ (IV) and $200 \mathrm{mg}$ (V). With the increasing amount of $\mathrm{Fe}_{3} \mathrm{O}_{4} \mathrm{MNPs}$, the saturated magnetization of $\mathrm{Fe}_{3} \mathrm{O}_{4} @$ PLGA-PEG- $\mathrm{NH}_{2}$ MNPs increased. The growth of the saturated magnetization gradually decelerated when the amount of $\mathrm{Fe}_{3} \mathrm{O}_{4}$ MNPs reached $800 \mathrm{mg}$. Therefore, $800 \mathrm{mg}$ of $\mathrm{Fe}_{3} \mathrm{O}_{4} \mathrm{MNPs}$ was considered as an optimized amount and used in the subsequent experiments.

In addition, the content of the free amino groups on the surface of MNPs was measured. The amino groups were determined by the ninhydrin assay with the absorbance at $420 \mathrm{~nm}$ measured with UV spectroscopy. A calibration curve was plotted based on the results at various PLGA-PEG- $\mathrm{NH}_{2}$ concentrations $(1.6,1.8,2.0,2.2,2.4 \mathrm{mg} / \mathrm{mL})$, from which the content of amino group was calculated using the following formula:

$$
A=0.2973 C-0.1348, R^{2}=0.9952
$$

where A represents the UV absorbance of samples, C represents the concentration of amino groups in the samples. Accordingly, when the amount of dichloromethane was $0.5 \mathrm{~mL}$, the concentration of PLGA-PEG-NH $\mathrm{N}_{2}$ on the MNPs was measured and calculated as $2.21 \mathrm{mg} / \mathrm{mL}$.

\subsection{Characterizations of $\mathrm{Fe}_{3} \mathrm{O}_{4} @ P L G A-P E G-\mathrm{NH}_{2}$ MNPs}

$\mathrm{Fe}_{3} \mathrm{O}_{4} @$ PLGA-PEG-NH $\mathrm{N}_{2}$ MNPs were characterized by TEM, VSM, particle size analyzer and zeta potential analyzer. The TEM image showed spherical morphology of the prepared MNPs (Figure 2A). Figure 2A showed that the $\mathrm{Fe}_{3} \mathrm{O}_{4} @ P L G A-P E G-\mathrm{NH}_{2}$ MNPs were dispersed in the system with an average diameter of approximately $143 \mathrm{~nm}$. The graph also showed that the $\mathrm{Fe}_{3} \mathrm{O}_{4}$ nanoparticles were distributed in the core of the $\mathrm{Fe}_{3} \mathrm{O}_{4} @$ PLGA-PEG-NH $\mathrm{N}_{2}$ MNPs with different numbers as the black dots, which may cause the particles to be heterogeneous. In addition, due to the air-drying process during the TEM sample preparation, the polymeric outer layer of the $\mathrm{Fe}_{3} \mathrm{O}_{4} @$ @LGA-PEG- $\mathrm{NH}_{2}$ MNPs might shrink and formed an outer dark layer in the TEM graph. Furthermore, the nanoparticles had a coercivity of 6 Oe (Figure S3A, in the Supplementary Materials) and a remanence of $0.005 \mathrm{emu} / \mathrm{g}$ (Figure S3B, in the Supplementary Materials). The average size of $\mathrm{Fe}_{3} \mathrm{O}_{4} @$ PLGA-PEG- $\mathrm{NH}_{2}$ MNPs was $141 \mathrm{~nm}$, with a PDI of 0.195 (Figure 2C), demonstrating excellent dispersion of the particles. The zeta potential of $\mathrm{Fe}_{3} \mathrm{O}_{4} @ P L G A-P E G-\mathrm{NH}_{2}$ MNPs was measured to be $17.36 \mathrm{mV}$ and considered to enable the nanoparticles to be relatively stable in the dispersed system. 
A

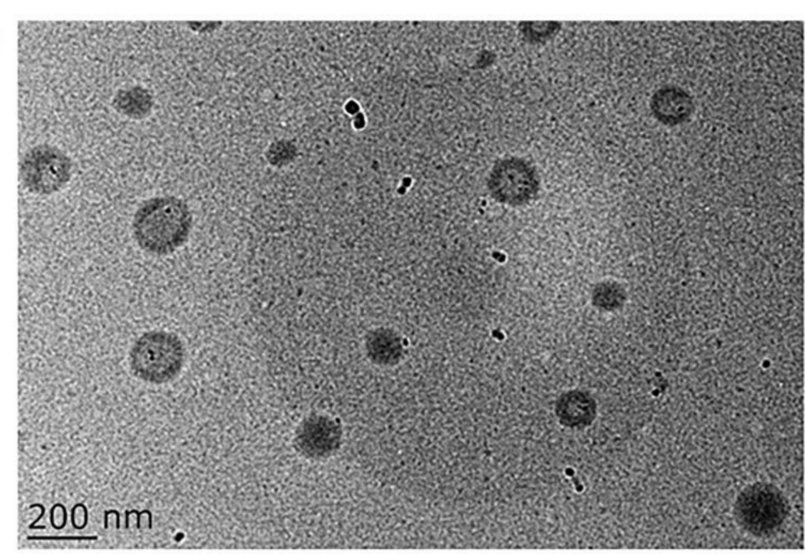

B

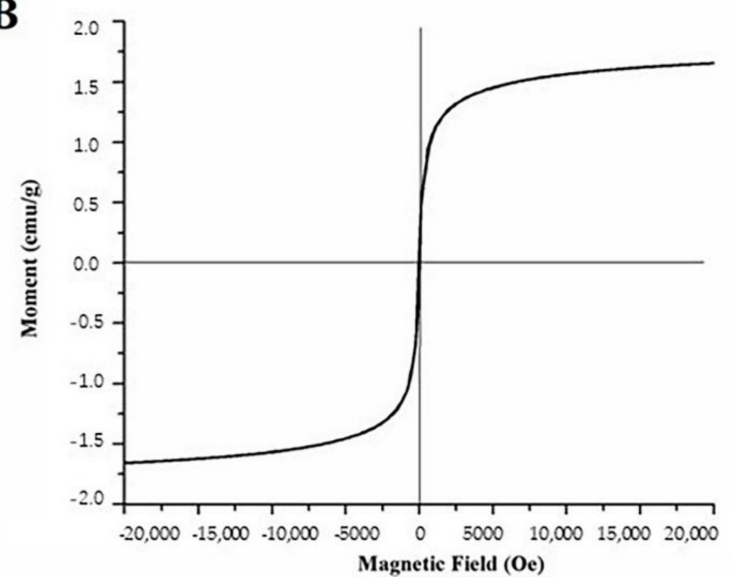

C Size Distribution by Intensity

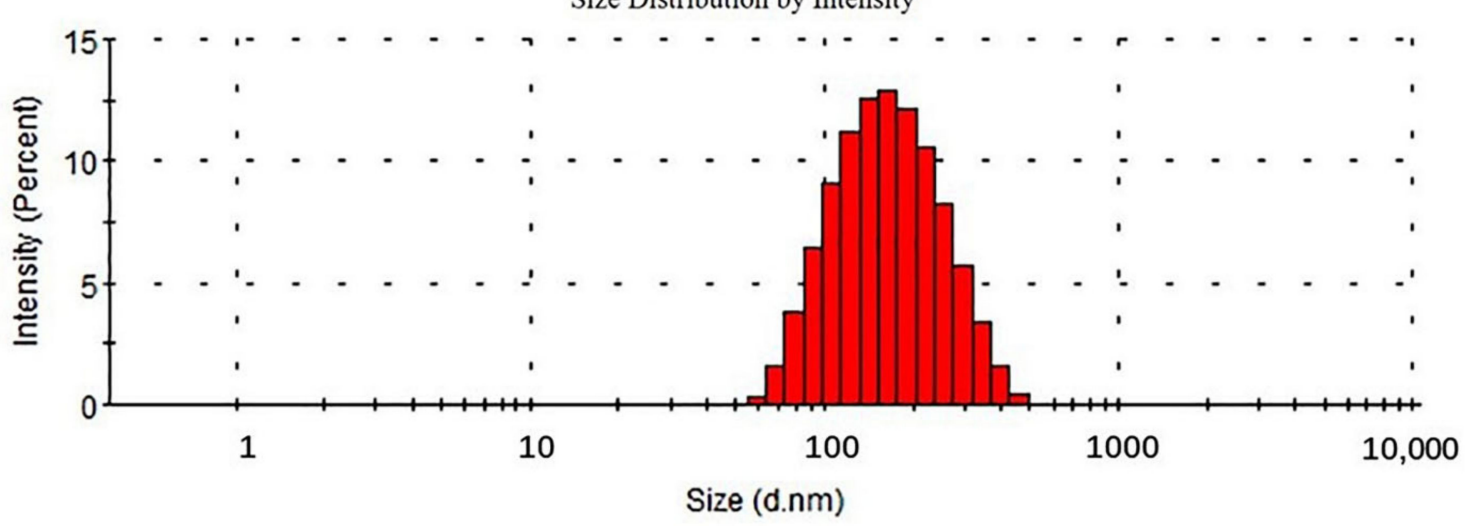

Figure 2. Characterizations of $\mathrm{Fe}_{3} \mathrm{O}_{4} @ P L G A-P E G-\mathrm{NH}_{2}$ MNPs. (A) TEM image; (B) hysteresis loop; (C) particle size distribution histogram.

\subsection{Activity Study of the Immobilized PLA 2}

Immobilization of enzyme onto the surface of MNPs has many advantages compared to the enzyme solutions [24]. Notably, immobilized enzymes are more stable and can be reused repeatedly. As far as we know, there are currently no $P_{2} A_{2}$-modified nanoparticulate systems reported for bioactive compounds screening. Enzymes can be immobilized on the surfaces by covalent bonding or non-covalent interactions. In this study, the covalent bonding method was selected because of the higher stability of the formed enzyme-polymer conjugates. The $\mathrm{PLA}_{2}$ molecules were conjugated onto the surface of $\mathrm{Fe}_{3} \mathrm{O}_{4} @ \mathrm{PLGA}-\mathrm{PEG}-$ $\mathrm{NH}_{2}$ MNPs with glutaraldehyde linkers to bridge the N-terminus of the $\mathrm{PLA}_{2}$ molecules and the amino groups on the surface of MNPs by robust covalent bonding.

The content of $-\mathrm{NH}_{2}$ groups on the surface of MNPs and $\mathrm{PLA}_{2}-\mathrm{MNPs}$ were measured by UV method based on the ninhydrin assay. Compared with MNPs, PLA - MNPs showed a lower UV absorbance at $420 \mathrm{~nm}$ because the number of $-\mathrm{NH}_{2}$ groups decreased after the reaction of $\mathrm{PLA}_{2}$ with $-\mathrm{NH}_{2}$ located on MNPs. It confirmed that the successful formation of $\mathrm{PLA}_{2}$-MNPs conjugates and the immobilization of the enzyme on $\mathrm{Fe}_{3} \mathrm{O}_{4} @$ PLGA-PEG$\mathrm{NH}_{2}$ MNPs.

It is necessary to measure the activities of the $\mathrm{PLA}_{2}$ before and after the immobilization to ensure that the conjugated enzymes are still active. Six standard PLA $\mathrm{P}_{2}$ concentrations $(0,1.25,2.5,5,10,20 \mathrm{U} / \mathrm{L})$ were tested to obtain a calibration curve and a linear regression equation. The enzyme concentrations of the samples were calculated using the following formula:

$$
\mathrm{Y}=-0.0056 \mathrm{X}^{2}+0.2624 \mathrm{X}+0.1188, \quad \mathrm{R}^{2}=0.9996
$$


where $\mathrm{Y}$ represents the OD of sample and $\mathrm{X}$ represents the concentration of enzyme.

Three experimental groups were set to determine the concentrations of immobilized $\mathrm{PLA}_{2}$ : (1) free PLA $\mathrm{PL}_{2}$; 2 PBS; (3) PLA 2 -MNPs prepared with different amounts of PLA According to the commercial provider, the enzymatic activity is 1.2-fold that of its concentration. As shown in Figure 3, enzymatic activity and the binding efficiency of immobilized enzyme increased significantly when the concentrations of enzyme increased from $200 \mathrm{U}$ to $600 \mathrm{U}$ and ceased to increase with higher concentrations of the enzyme. Therefore, $\mathrm{PLA}_{2}$ immobilization was carried out with $600 \mathrm{U} \mathrm{PLA}_{2}$ in a subsequent immobilization process. When the amount of PLA 2 was $600 \mathrm{U}$, the concentrations of free $\mathrm{PLA}_{2}$ and immobilized enzyme were calculated to be $1.934 \mathrm{U} / \mathrm{L}$ and $1.52 \mathrm{U} / \mathrm{L}$, respectively, and the corresponding enzyme activity levels were $2.321 \mathrm{U}$ and $1.824 \mathrm{U}$, respectively. The activity of PLA $\mathrm{A}_{2}$-MNPs was nearly $80 \%$ of that of free enzyme. The results showed that $\mathrm{PLA}_{2}$ had been successfully immobilized onto $\mathrm{Fe}_{3} \mathrm{O}_{4} @$ PLGA-PEG-NH $\mathrm{N}_{2}$ MNPs, in which the enzymatic activity of PLA was mostly maintained and ready for use thereafter.
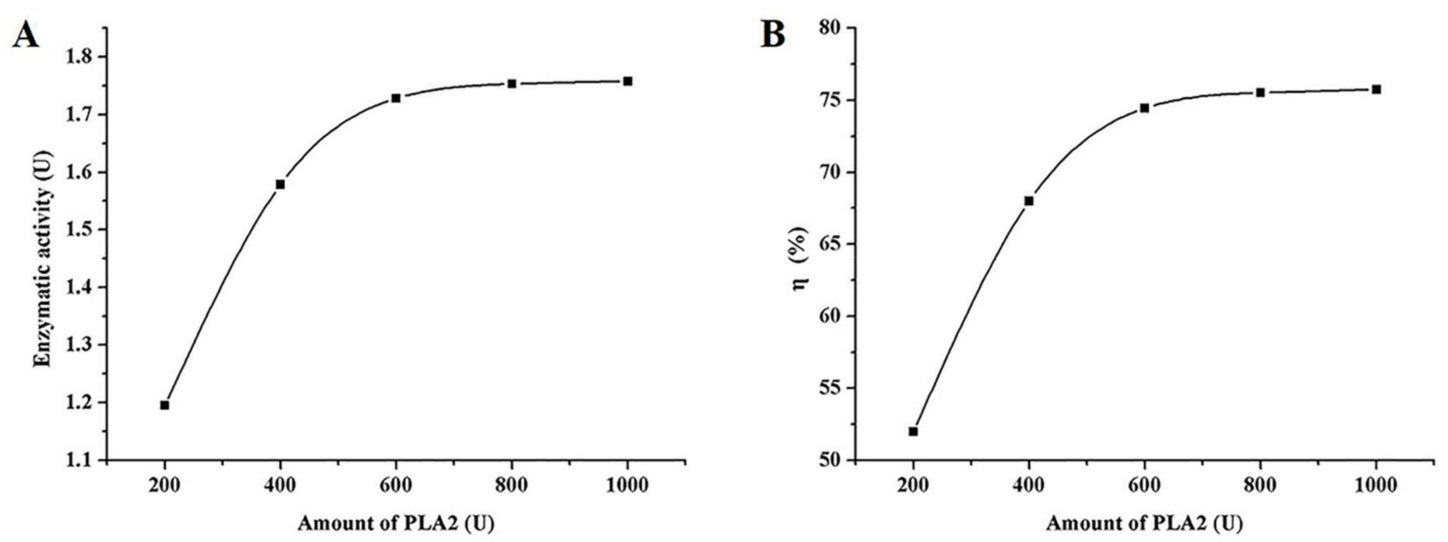

Figure 3. Influence of amounts of $\mathrm{PLA}_{2}$ on (A) enzymatic activity and (B) the binding efficiency of immobilized enzyme.

\subsection{Validation of the Ligand Fishing Assay}

The mixture (a) of dexamethasone, curcumin and tanshinone IIA, the supernatant (b) after ligand fishing, and the ligand (c) fished by $\mathrm{PLA}_{2}-\mathrm{MNPs}$ were obtained and analyzed by HPLC referring to 3.7. Dexamethasone was chosen as a positive control to assess the specificity of the ligand fishing using a combination of PLA - MNPs and LC-MS. The HPLC chromatograms revealed that tanshinone IIA and curcumin (negative controls) did not bind to PLA $\mathrm{A}_{2}$ enzyme as they were washed off gradually in $\mathrm{b}$ and did not appear in $\mathrm{c}$ at all. On the contrary, dexamethasone was clearly observed in elute c, which showed that dexamethasone was successfully maintained and fished out with the highest amount and confirmed the specificity of the proposed method (Figure 4). 


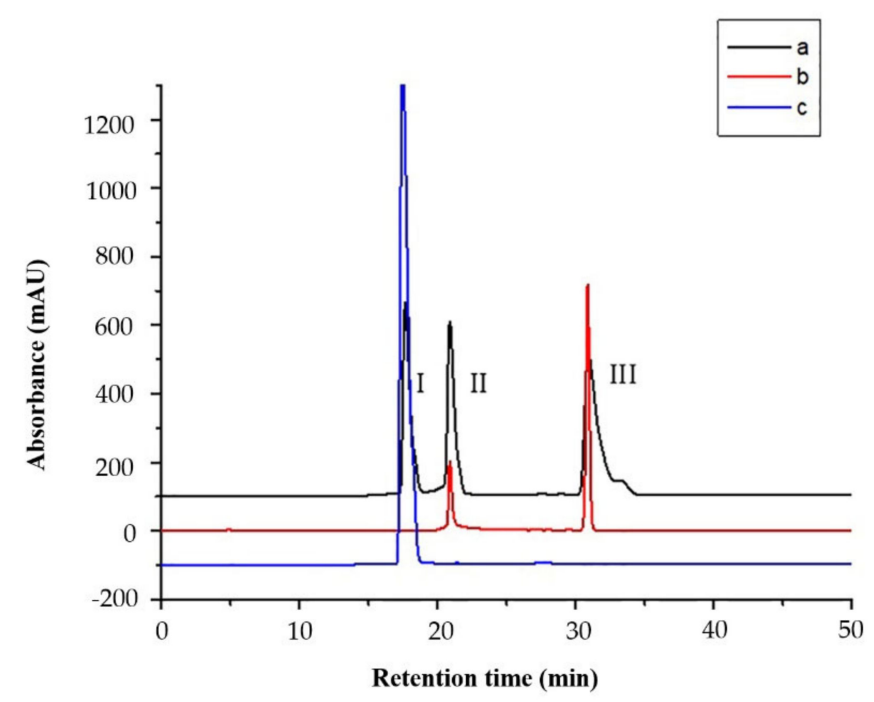

Figure 4. HPLC chromatograms $(254 \mathrm{~nm})$ of (a) the ligand fishing experiment with a prepared test mixture consisting of dexamethasone (I), tanshinone IIA (II) and curcumin (III). Non-binders II and III were washed out (b), whereas binder I was eluted with methanol (c).

\subsection{Ligand Fishing and LC-MS of Ligands}

The HPLC chromatograms of original extract of fungus Pseudopithomyces sp. 1512101 (red line) and elution fractions after ligand fishing by $\mathrm{PLA}_{2}$ (blue line) were compared (Figure 5). The HPLC chromatogram of eluent fractions after PLA 2 ligand fishing was significantly simpler and clearer than that of the unfished fungal extracts, implying that considerable substances without affinities to $\mathrm{PLA}_{2}$ were washed off and $\mathrm{PLA}_{2}$-MNPs showed efficient separation of target components. The total ion chromatogram of target ligands is also shown in Figure 6.

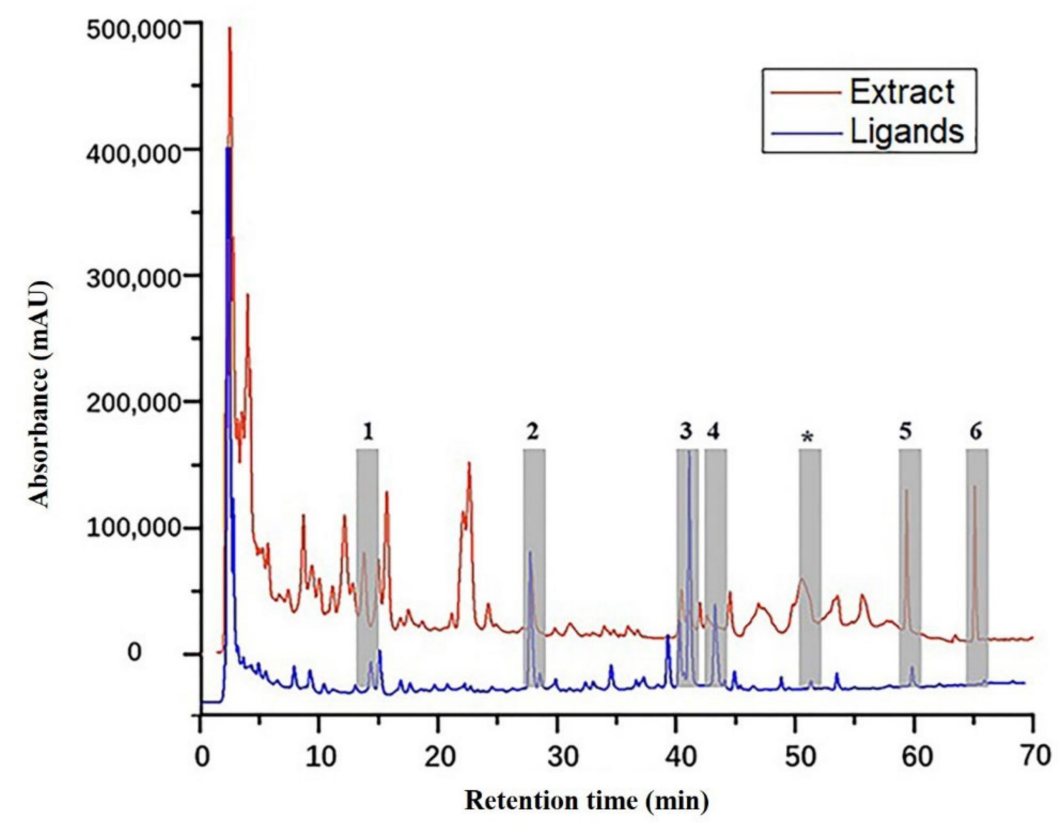

Figure 5. HPLC chromatograms of the ligands and extract. 


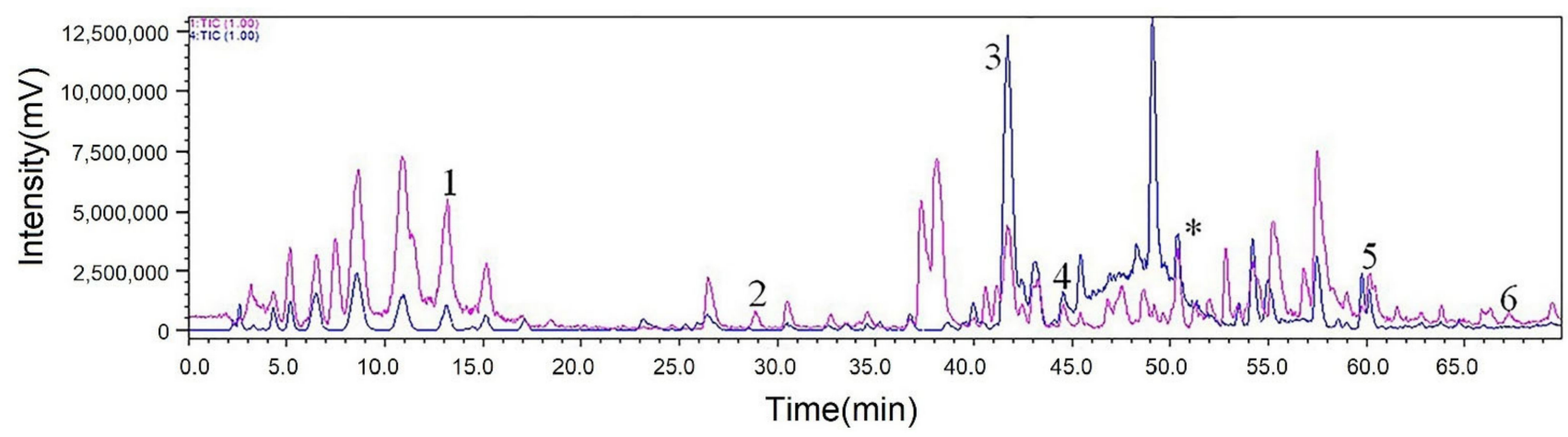

Figure 6. Total ion chromatograms of ligands (positive ion mode: red line; negative ion mode: blue line). The peak "*” which appeared to be a fatty acid compound.2.7. Identification of Ligands and Evaluation of Their Cytotoxicity.

After separation and purification, six compounds 1-6 (Figure 5) were obtained from the extract of fungus Pseudopithomyces sp. 1512101. By comparing the retention time (Rt) and MS with fished ligands, apart from the peak "** which appeared to be a fatty acid compound with extremely low polarity and failed to be isolated and identified, six compounds were obtained and identified as ligand compounds. Their retention times and molecular ion peaks are listed in Table 1.

Table 1. LC-MS data of ligands found in fungal extracts.

\begin{tabular}{ccccc}
\hline Compound & Rt (min) & Formula & + ESI, $\mathbf{m} / \mathbf{z}$ & $-\mathbf{E S I}, \mathbf{m} / \mathbf{z}$ \\
\hline $\mathbf{1}$ & 13.124 & $\mathrm{C}_{11} \mathrm{H}_{18} \mathrm{~N}_{2} \mathrm{O}_{3}$ & 453.3417 & 487.3021 \\
$\mathbf{2}$ & 28.860 & $\mathrm{C}_{10} \mathrm{H}_{16} \mathrm{~N}_{2} \mathrm{O}_{2}$ & 219.1898 & - \\
$\mathbf{3}$ & 41.381 & $\mathrm{C}_{25} \mathrm{H}_{43} \mathrm{~N}_{3} \mathrm{O}_{6}$ & $482.3256,504.3039$ & 516.2833 \\
$\mathbf{4}$ & 44.528 & $\mathrm{C}_{28} \mathrm{H}_{44} \mathrm{O}_{3}$ & 451.3171 & 463.2874 \\
$\mathbf{5}$ & 60.197 & $\mathrm{C}_{28} \mathrm{H}_{44} \mathrm{O}$ & 397.4140 & 431.3750 \\
$\mathbf{6}$ & 67.295 & $\mathrm{C}_{28} \mathrm{H}_{46} \mathrm{O}_{3}$ & - & 429.2816, \\
& & & & 465.2551 \\
\hline
\end{tabular}

The structures of cyclo-(4-hydroxyl-Pro-Leu) (1) [25], cyclo-(Pro-Val) (2) [26], fusaristatin C (3) [27], ergosterol peroxide (4) [28], ergosterol (5) [29] and cerevisterol (6) [30] (Figure 7) were elucidated by comparison with previously reported NMR spectroscopy and MS data. Their ${ }^{1} \mathrm{H}$ and ${ }^{13} \mathrm{C}$ NMR spectroscopy data are shown in Table S1 (in the Supplementary Materials).

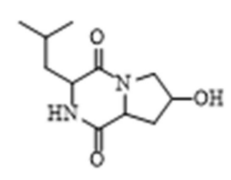

1

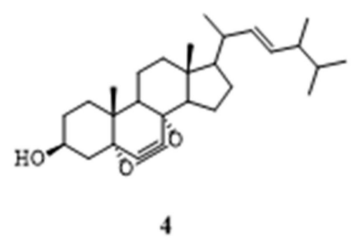

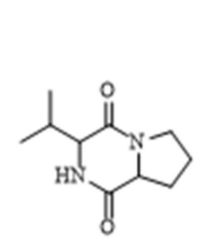

2

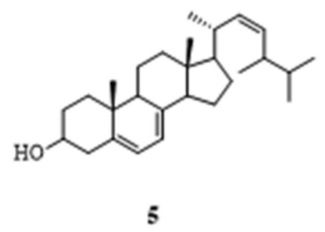

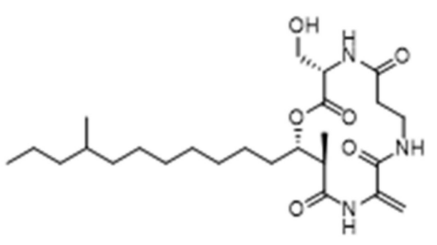

3

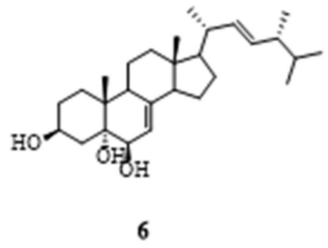

Figure 7. Chemical structures of the isolated ligands.

Human lung carcinoma cell line A549, bone marrow neuroblastoma cell line SH-SY5Y and cervical cancer cell line HeLa were selected for cytotoxicity experiment as $\mathrm{PLA}_{2}$ has 
been recognized as an important drug target for the initiation and progression of these types of cancers. The results of $\mathrm{PLA}_{2}$ inhibitory assay demonstrated that compound 3 had an inhibitory effect when the concentration was $60 \mu \mathrm{M}$ and $100 \mu \mathrm{M}$ (Table S2, in the Supplementary Materials). According to previous literatures, compounds 1, 2 and 4-6 have been reported with various degrees of cytotoxicity against human cancer cells (Table 2). Therefore, only compound $\mathbf{3}$ was selected to test its inhibitory activities against human cancer cells in this study. Among the in vitro tests of compound 3 against human lung carcinoma cell line A549, bone marrow neuroblastoma cell line SH-SY5Y and cervical cancer cell line HeLa, the MTT assay revealed that A549 cell line was the most sensitive to the compound 3 and its $\mathrm{IC}_{50}$ was calculated to be around $10.10 \mu \mathrm{M}$ (Table 2), lower than the reported results of the other compounds, apart from the result of compound 4 against K562 cell line. The results suggested that compound 3 was a promising inhibitor for PLA 2 and a potential lead compound worthy of further antitumor drug research.

Table 2. Effects of ligand compounds on tumor cells.

\begin{tabular}{|c|c|}
\hline Ligand Compound & Cytotoxicity \\
\hline Compound 1 & $\begin{array}{l}\text { Human chronic myelogenous leukemia cell line K562 (367.38 } \mu \mathrm{M}, 33.3 \%) \text { [31]. } \\
\text { Mouse breast cancer cell line tsFT210 }(25.35 \mu \mathrm{M},(13.3 \pm 1.6 \%) \text { [32]. }\end{array}$ \\
\hline \multirow[t]{2}{*}{ Compound 2} & Liver cancer cell line HepG2 $(253.55 \mu \mathrm{M}, 17 \%)[33]$ \\
\hline & Prostate cancer cell line LNCaP (253.55 $\mu \mathrm{M}, 53 \%)$ [33]. \\
\hline Compound 3 & Human lung carcinoma cell line A549 $\left(\mathrm{IC}_{50}=10.10 \mu \mathrm{M}\right)$. \\
\hline Compound 4 & $\begin{array}{l}\text { Human chronic myelogenous leukemia cell line } \mathrm{K} 562\left(\mathrm{IC}_{50}=4.30 \mu \mathrm{M}\right)[34] \\
\text { Cervical cancer cell line HeLa }\left(\mathrm{IC}_{50}=15.76 \mu \mathrm{M}\right)[35] .\end{array}$ \\
\hline Compound 5 & $\begin{array}{l}\text { Human chronic myelogenous leukemia cell line } \mathrm{K} 562\left(\mathrm{IC}_{50}=40.17 \mu \mathrm{M}\right)[34] . \\
\text { Breast cancer cell line MCF-7 }\left(\mathrm{IC}_{50}=112.65 \mu \mathrm{M}\right)[36] .\end{array}$ \\
\hline Compound 6 & $\begin{array}{l}\text { Human chronic myelogenous leukemia cell line } \mathrm{K} 562\left(\mathrm{IC}_{50}=169.68 \mu \mathrm{M}\right)[34] . \\
\text { Breast cancer cell line MCF-7 }\left(\mathrm{IC}_{50}=429.03 \mu \mathrm{M}\right)[36] .\end{array}$ \\
\hline
\end{tabular}

\section{Experimental Section}

\subsection{Materials and Chemicals}

Poly(dl-lactic-co-glycolic acid) 50/50 (PLGA-COOH, MW 10,000) was purchased from Shandong Medical Equipment Institute (Jinan, China). Polyethylene glycol bis-amine $\left(\mathrm{NH}_{2}\right.$-PEG-NH $\mathrm{NH}_{2}, \mathrm{MW}$ 2000) was obtained from $\mathrm{Xi}^{\prime}$ an Ruixi Biotechnology Co., Ltd. (Xi' an, China). N-Hydroxysuccinimide (NHS), dicyclohexylcarbodiimide (DCC), polyvinyl alcohol (PVA, MW 3100), $\mathrm{PLA}_{2}$ ( $\mathrm{PLA}_{2}$ from porcine pancreas), deuterated reagent and methyl thiazolyl tetrazolium (MTT) were obtained from Sigma-Aldrich (Shanghai, China). $\mathrm{Fe}_{3} \mathrm{O}_{4}$ MNPs (20 nm) were bought from Shanghai Ziming Biotechnology Co., Ltd. (Shanghai, China). Glutaraldehyde solution (3 wt \%) and tris(hydroxymethyl)methyl aminomethane (Tris) were provided by Aladdin Chemistry (Shanghai, China). Dexamethasone was obtained from Hubei Yuancheng Saichuang Technology Co., Ltd. (Hubei, China). Curcumin was obtained from Shanghai Maclean Biochemistry Co., Ltd. (Shanghai, China). Tanshinone IIA was obtained from Shenzhen Meihe Biological Technology Co., Ltd. (Shenzhen, China). Sodium cyanoborohydrid and 5-Fluorouracil (5-FU) were obtained from Shanghai Macklin Biochemical Co., Ltd. (Shanghai, China). PLA 2 ELISA kit was purchased from Shanghai Lichen Biotechnology Co., Ltd. (Shanghai, China). Potato dextrose agar (PDA), glucose, peptone, yeast extract and sea salt were obtained from Guangdong Huankai Microbial Sci. \& Tech. Co., Ltd. (Guangzhou, China). Methanol (MeOH) was obtained from Merck (HPLC-grade, Darmstadt, Germany). Column chromatography silica gel (200-300 mesh) was obtained from Qingdao Ocean Chemical Co., Ltd. (Qingdao, China). Sephadex LH-20 was obtained from GE Healthcare Bio-Sciences AB (Shanghai, China). DMEM and 1640 medium were obtained from Gibco (California, USA). The solvents and reagents used in this study were classified as analytical grade.

\subsection{Fungal Strain}

The fungus 1512101 was isolated from the leaves of mangrove plant Sonneratia caseolaris, which was collected in October 2015 from the Nansha Mangrove Nature Reserve 
in Guangzhou, China. The fungal strain was identified to be most similar (99\%) to that of Pseudopithomyces sp. 1512101 (compared to MF919624.1). The voucher specimen was stored in our laboratory at $4{ }^{\circ} \mathrm{C}$.

\subsection{Cell Culture}

A549, SH-SY5Y and HeLa cells were generously provided by Professor Mao (School of Pharmacy, Guangdong Pharmaceutical University, China). They were incubated in DMEM and 1640 medium (containing $100 \mathrm{U} / \mathrm{mL}$ penicillin, $10 \%(v / v)$ fetal bovine serum and $100 \mu \mathrm{g} / \mathrm{mL}$ streptomycin) in an incubator $\left(5 \% \mathrm{CO}_{2}, 37^{\circ} \mathrm{C}\right)$.

\subsection{Apparatus and Characterization}

UV absorptions were measured using a UV-2550 spectrophotometer (Shimadzu, Kyoto, Japan). All surface functional groups were detected in $\mathrm{KBr}$ using a Fourier transform infrared (FTIR) spectrometer (Perkin Elmer, Waltham, MA, USA). The morphology of nanomaterials was observed using a JEM-3100F transmission electron microscope (TEM, JEOL Co., Tokyo, Japan). The particle size of nanomaterials was measured using a Malvern Nano S90 particle size analyzer (Malvern, UK). The zeta potential was recorded on a Delsa TM Nano laser nanoparticle analyzer (Beckman Coulter, Inc., Brea, CA, USA). The magnetic properties were tested with a MPMA XL-7 vibrating sample magnetometer (VSM, Quantum Design, CA, USA). Nanoparticles were freeze-dried using an LGJ-10 freeze dryer (Beijing Songyuan Huaxing Technology Development Co., Ltd., Beijing, China). A YM75 vertical autoclave (Shanghai Sanshen Medical Equipment Co., Ltd., Shanghai, China) was used to sterilize culture medium. A SPX-250C constant temperature and humidity incubator (Shanghai Boxun Industrial Co., Ltd. Medical Equipment Factory, Shanghai, China) and TCYQ shaker (Taicang Experimental Equipment Factory, China) were used for culturing strains. The inhibitory activities of ligands were determined using a Multiskan FC microplate reader (Thermo Fisher Scientific, Waltham, MA, USA). HPLCMS, carrying out on an Agilent 6120 LC system (Agilent Technologies, Santa Clara, CA, USA), was equipped with a 6520 quadrupole-time-of-flight mass spectrometer (Agilent Technologies, Santa Clara, CA, USA) using an ESI ion source. A Bruker Avance III 400 NMR spectrometer (Bruker, Germany) was employed to obtain the ${ }^{1} \mathrm{H}$ NMR $(400 \mathrm{MHz})$ and ${ }^{13} \mathrm{C}$ NMR (100 MHz) spectra of the samples using TMS as an internal standard. A Micromass LCT mass spectrometer (Waters, USA) was used to measure the ESI-TOF mass spectra of the sample, and the accurate mass was determined and calibrated using a lock mass setup. Cells were cultured in an HER Acell 150i incubator (Thermo Fisher Scientific, Waltham, MA, USA).

\subsection{Preparation of $P L A_{2}-M N P S$}

\subsubsection{Preparation of PLGA-PEG-NH $\mathrm{NH}_{2}$ di-block Copolymer}

PLGA-PEG-NH $\mathrm{N}_{2}$ di-block copolymer was synthesized with the formation of amide linkage between $\mathrm{NH}_{2}$-PEG- $\mathrm{NH}_{2}$ and activated PLGA-COOH as described in previous studies [37-41]. PLGA-COOH (100 mg, $0.01 \mathrm{mmol}), 5$ molar excesses of NHS (5.6 mg, $0.05 \mathrm{mmol})$ and DCC (10.3 $\mathrm{mg}, 0.05 \mathrm{mmol})$ were dissolved in anhydrous dichloromethane (DCM). The mixture was stirred under $\mathrm{N}_{2}$ at room temperature for $24 \mathrm{~h}$ to activate the carboxyl group of PLGA-COOH. The resulted solution was filtered to remove the formed dicyclohexylurea. The activated PLGA was added dropwise to excess amount of $\mathrm{NH}_{2}$ PEG-NH $\mathrm{NH}_{2}(100 \mathrm{mg}, 0.05 \mathrm{mmol})$ dissolved in anhydrous DCM with gentle stirring. The stoichiometry of PLGA-COOH/NH $2-\mathrm{PEG}-\mathrm{NH}_{2}$ was 1:5. The mixture was allowed to be reacted for another $24 \mathrm{~h}$ under room temperature. The DCC and NHS were removed from the concentrated solution by precipitation in ice-cold diethyl ether. The amine-terminated PEG-PLGA-NH $\mathrm{N}_{2}$ di-block copolymer was further purified in excess-cold methanol and lyophilized to afford the final product. 


\subsubsection{Preparation of $\mathrm{Fe}_{3} \mathrm{O}_{4} @ P L G A-P E G-\mathrm{NH}_{2} \mathrm{MNPs}$}

$\mathrm{Fe}_{3} \mathrm{O}_{4} @$ PLGA-PEG-NH $\mathrm{N}_{2}$ MNPs were prepared with a classical solvent emulsion/ evaporation method [42,43]. Briefly, $800 \mathrm{mg}$ of $\mathrm{Fe}_{3} \mathrm{O}_{4}$ MNPs and $100 \mathrm{mg}$ of PLGA-PEG-NH were suspended in $0.5 \mathrm{~mL}$ of dichloromethane by vortex, giving an oil phase that was then added to $2 \mathrm{~mL}$ of $3 \mathrm{wt} \%$ aqueous PVA solution and sonicated for $2 \mathrm{~min}$. The emulsion was subsequently added to $15 \mathrm{~mL}$ of $1 \mathrm{wt} \%$ PVA solution, and the organic phase was removed through reduced pressure evaporation. The dispersion was centrifuged at $6000 \mathrm{rpm}$ for 20 min to remove the unencapsulated $\mathrm{Fe}_{3} \mathrm{O}_{4}$ MNPs. The prepared $\mathrm{Fe}_{3} \mathrm{O}_{4} @$ PLGA-PEG- $\mathrm{NH}_{2}$ MNPs product was then freeze-dried and stored at $4{ }^{\circ} \mathrm{C}$.

During the synthesis of $\mathrm{Fe}_{3} \mathrm{O}_{4} @$ PLGA-PEG-NH $\mathrm{N}_{2}$ MNPs, the effects of different reaction conditions on the magnetic properties of MNPs, including preparation methods and amounts of $\mathrm{Fe}_{3} \mathrm{O}_{4}$ MNPs, were assessed.

\subsubsection{Preparation of $\mathrm{PLA}_{2}$-MNPs}

$\mathrm{PLA}_{2}$ was bound onto the surface of $\mathrm{Fe}_{3} \mathrm{O}_{4} @$ PLGA-PEG-NH${ }_{2}$ MNPs in the form of Schiff base linked by glutaraldehyde. Briefly, $16 \mathrm{mg}$ of $\mathrm{Fe}_{3} \mathrm{O}_{4} @$ PLGA-PEG- $\mathrm{NH}_{2} \mathrm{MNPs}$ were suspended in PBS ( $0.01 \mathrm{M}, \mathrm{pH} 7.7)$ and vortexed for $10 \mathrm{~min}$. Subsequently, $20 \mathrm{mg}$ of sodium cyanoborohydride and $1 \mathrm{~mL}$ of $3 \mathrm{wt} \%$ glutaraldehyde were added to the solution and oscillated at $37^{\circ} \mathrm{C}$ for $3 \mathrm{~h}$. Afterwards, the aldehyde-activated MNPs were magnetically separated from the supernatant using a magnet and washed twice with PBS to remove excess glutaraldehyde. Then, the activated $\mathrm{Fe}_{3} \mathrm{O}_{4} @$ PLGA-PEG- $\mathrm{NH}_{2}$ MNPs linked with glutaraldehyde were added to PBS containing $600 \mathrm{U}$ of $\mathrm{PLA}_{2}$. The solution was vibrated at $37^{\circ} \mathrm{C}$ for 2 days. After immobilization, the $\mathrm{PLA}_{2}$-immobilized nanoparticles were rinsed twice with water, redispersed in Tris- $\mathrm{HCl}$ buffer $(1 \mathrm{M}, \mathrm{pH} 8)$ and stored at $4{ }^{\circ} \mathrm{C}$ prior to use. During the preparation of PLA $-\mathrm{MNPs}$, the effects of various amounts of PLA 2 on the enzymatic activity of MNPs were also assessed.

\subsection{Enzyme Activity Assay}

The activity of $\mathrm{PLA}_{2}$ was tested using an ELISA kit. Enzymatic reactions were performed on a 96-well microplate. Free PLA 2 and immobilized PLA $\mathrm{P}_{2}$ were dissolved in PBS (0.01 M, pH 7.7). PLA 2 was preincubated with HRP-conjugate reagent at $37^{\circ} \mathrm{C}$ for $1 \mathrm{~h}$, followed by addition of substrate chromogen solution A (trimethoxybenzaldehyde) and chromogen solution B (tetramethylbenzidine), and incubation at $37^{\circ} \mathrm{C}$ for $15 \mathrm{~min}$ till the stopping buffer was added into each well. The optical density (OD) of the sample was measured using a microplate reader $(450 \mathrm{~nm})$. A standard curve of the samples was plotted using the averaged OD values of six standard concentrations. Finally, the concentration of $\mathrm{PLA}_{2}$ was determined by comparing OD value of the sample to the standard curve.

\subsection{Establishment and Validation of Ligand Fishing Assay}

Dexamethasone, a typical $\mathrm{PLA}_{2}$ inhibitor, was chosen as the positive control for the verification of the proposed method. Dexamethasone, curcumin and tanshinone IIA ( $2 \mathrm{mM}$ each, equimolar) were mixed in PBS as a model sample (a). Three $\mathrm{mL}$ of the model sample were added to $\mathrm{PLA}_{2}$-MNPs dispersion and incubated for $3 \mathrm{~h}$ at $50^{\circ} \mathrm{C}$. After magnetic separation, the supernatant (b) was collected and the MNPs were washed 3 times with PBS. One $\mathrm{mL}$ of methanol was used to redisperse the $\mathrm{PLA}_{2}-\mathrm{MNPs}$ for $1 \mathrm{~h}$ to dissociate bound components. After separation, the supernatant (c), the mixture a and the supernatant $b$ were collected and analyzed by HPLC after filtration. The column temperature was set at $25^{\circ} \mathrm{C}$. The eluent flow rate was $0.5 \mathrm{~mL} / \mathrm{min}$. The mobile phase consisted of solvent $\mathrm{A}$ (methanol) and solvent $\mathrm{B}(0.1 \%, v / v$, formic acid/water). The gradient elution program was optimized as below: $50-85 \% \mathrm{~A}$ at $0-10 \mathrm{~min}, 85 \% \mathrm{~A}$ at $10-25 \mathrm{~min}, 85-90 \% \mathrm{~A}$ at $25-30 \mathrm{~min}$, $90 \%$ A at $30-40 \mathrm{~min}$. The sample injection volume was $20.0 \mu \mathrm{L}$. 


\subsection{Fishing Potential Ligands from Fungal Extract}

\subsubsection{Preparation of Fungal Extract}

The fresh mycelia of Pseudopithomyces sp. 1512101 were grown on PDA medium at $28{ }^{\circ} \mathrm{C}$ for 3-4 days and then inoculated into conical flasks $(500 \mathrm{~mL})$ containing $250 \mathrm{~mL}$ of PYG medium (10 g/L glucose, $2 \mathrm{~g} / \mathrm{L}$ peptone, $1 \mathrm{~g} / \mathrm{L}$ yeast extract, $2 \mathrm{~g} / \mathrm{L}$ sea salt, $\mathrm{pH}$ 6.0-7.0). After incubation for $3-4$ days at $28^{\circ} \mathrm{C}$ on a rotary shaker at $120 \mathrm{rpm}, 5 \mathrm{~mL}$ of the culture medium was transferred as the seed into $500 \mathrm{~mL}$ flasks containing PYG medium $(250 \mathrm{~mL})$. The conical flasks were then incubated for a month at room temperature $\left(25-30^{\circ} \mathrm{C}\right)$. Subsequently, the whole fermented cultures $(150 \mathrm{~L})$ were filtered through cheesecloth. The mycelia were separated to obtain a culture broth. Ethyl acetate was added to the culture broth for extraction until the upper layer became colorless, while the mycelia were extracted 3 times with methanol and concentrated. Subsequently, the concentrate was further extracted with ethyl acetate and concentrated to obtain the crude extract (38.4 g).

\subsubsection{Application of Ligand Fishing in Fungal Extract}

The above fungal extract $(3 \mathrm{~mL}, 1 \mathrm{mg} / \mathrm{mL})$ was incubated at $50{ }^{\circ} \mathrm{C}$ with $\mathrm{PLA}_{2}-\mathrm{MNPs}$ for $3 \mathrm{~h}$. After the separation process, $\mathrm{PLA}_{2}$-MNPs were taken out and washed 3 times with PBS to remove the components with no or low affinity to $\mathrm{PLA}_{2}$ followed by incubation in methanol $(1 \mathrm{~mL})$ for $1 \mathrm{~h}$ to dissociate the specifically bound components. The methanol solution containing potential ligands was collected.

\subsection{Analysis of Ligands by LC-MS}

LC-MS technology was used to analyze the obtained ligands. A Phenomenex C18 column $(250 \mathrm{~mm} \times 4.6 \mathrm{~mm}, 4.5 \mu \mathrm{m})$ was used for chromatographic separation. The column temperature was maintained at $25^{\circ} \mathrm{C}$. The eluent flow rate was set at $1 \mathrm{~mL} / \mathrm{min}$, and the mobile phase consisted of solvent $\mathrm{A}$ (methanol) and solvent $\mathrm{B}(0.1 \%, v / v$, formic acid/water). The gradient elution program was optimized as below: $50 \% \mathrm{~A}$ at $0-5 \mathrm{~min}, 50-90 \% \mathrm{~A}$ at $5-45 \mathrm{~min}, 90-100 \% \mathrm{~A}$ at $45-60 \mathrm{~min}$ and $100 \% \mathrm{~A}$ at $60-70 \mathrm{~min}$. The injection volume of the sample was set as $20.0 \mu \mathrm{L}$. MS data were acquired in the positive/negative ion mode by ESI and analyzed by PeakView $1.2^{\circledR}$ Software.

\subsection{Isolation of Ligands}

Next, $38.4 \mathrm{~g}$ of extract were separated on a silica gel column with gradient elution by using petroleum ether/ethyl acetate (90:10, 70:30, 50:50, 30:70, 0:100, v/v) and ethyl acetate/methanol (50:50, 0:100, v/v) to yield 15 fractions (Frs. 1-15). The retention time of the contents in each fraction was compared with that of ligands fished out under the same HPLC conditions. Frs. 4-9 were further separated by column chromatography including silica gel, preparative chromatography and Sephadex LH-20 column, giving target compounds 1-6.

\subsection{In Vitro Cytotoxicity Assay}

Compound 3 was evaluated for its inhibitory activities against $\mathrm{PLA}_{2}$ using a sPLA inhibitor screening assay kit firstly. Then, the cytotoxicities of compound 3 against human lung carcinoma cell line A549, bone marrow neuroblastoma cell line SH-SY5Y and cervical cancer cell line HeLa were determined by the MTT assay. The cells were subcultured when $80-90 \%$ confluence was reached, seeded in a 96-well microplate at the density of $5 \times 104 / \mathrm{mL}$ per well and incubated with various concentrations of compound 3 for $24 \mathrm{~h}$. After, 5-FU was used as the positive control. The cells were treated with $10 \mu \mathrm{L}$ of MTT in PBS $(5 \mathrm{mg} / \mathrm{mL})$ and then incubated for another $4 \mathrm{~h}$. The cells were dissolved in $100 \mu \mathrm{L}$ of dimethyl sulfoxide. Finally, the OD of the sample at $490 \mathrm{~nm}$ was measured and recorded using a microplate reader. 


\section{Conclusions}

In summary, a new strategy using ligand fishing based on PLA A $_{2}$ MNPs with LC-MS was established to separate and analyze bioactive components from natural products. Using this strategy, six ligands of $\mathrm{PLA}_{2}$ were rapidly extracted and identified from mangrove endophytic fungi. Furthermore, the cytotoxicity of these compounds was also evaluated. This robust and relatively convenient ligand fishing approach using PLA $\mathrm{A}_{2}-\mathrm{MNPs}$ can be applied to screen more antitumor ingredients from natural extracts. In the future, we can construct a new nanoparticle system to load targeted enzyme compounds for the treatment of cancer in vivo.

Supplementary Materials: The following are available online: Table S1: Names, MS, ${ }^{1} \mathrm{H}$ and ${ }^{13} \mathrm{C}$ NMR spectroscopy data of identified compounds from the crude extract of endophytic fungus Pseudopithomyces sp. 1512101, Table S2: Assessment the inhibition of enzymatic activity with different amounts of compound 3, Figure S1: FTIR spectrum of $\mathrm{Fe}_{3} \mathrm{O}_{4} @$ PLGA-PEG-NH $\mathrm{H}_{2}$ MNPs, Figure S2: (A) Hysteresis loops of $\mathrm{Fe}_{3} \mathrm{O}_{4} @$ PLGA-PEG- $\mathrm{NH}_{2}$ MNPs by single emulsions $(\mathrm{o} / \mathrm{w})$ and multiple emulsions ( $\mathrm{w} / \mathrm{o} / \mathrm{w}$ ); size (B), PDI (C) and hysteresis loops (D) of $\mathrm{Fe}_{3} \mathrm{O}_{4} @$ PLGA-PEG-NH $\mathrm{N}_{2}$ MNPs with different amounts of $\mathrm{Fe}_{3} \mathrm{O}_{4}$ MNPs, Figure S3: (A) Coercive force of $\mathrm{Fe}_{3} \mathrm{O}_{4} @$ PLGA-PEG-NH $\mathrm{N}_{2}$ MNPs; (B) remanence of $\mathrm{Fe}_{3} \mathrm{O}_{4} @$ PLGA-PEG-NH $\mathrm{N}_{2}$ MNPs, Figure S4: UV-Vis absorption spectra of PLA ${ }_{2}-$ MNPs and $\mathrm{Fe}_{3} \mathrm{O}_{4} @$ PLGA-PEG-NH ${ }_{2}$ MNPs, Figure S5: ${ }^{1} \mathrm{H}-\mathrm{NMR}$ spectra of compound 1, Figure S6: ${ }^{13} \mathrm{C}-\mathrm{NMR}$ spectra of compound 1, Figure S7: MS Spectra of compound 1, Figure S8: ${ }^{1} \mathrm{H}-\mathrm{NMR}$ spectra of compound 2, Figure S9: ${ }^{13} \mathrm{C}-\mathrm{NMR}$ spectra of compound 2, Figure S10: MS Spectra of compound 2, Figure S11: ${ }^{1} \mathrm{H}-\mathrm{NMR}$ spectra of compound 3, Figure S12: ${ }^{13} \mathrm{C}-\mathrm{NMR}$ spectra of compound 3, Figure S13: MS Spectra of compound 3, Figure S14: ${ }^{1} \mathrm{H}-\mathrm{NMR}$ spectra of compound 4, Figure S15: ${ }^{13} \mathrm{C}-\mathrm{NMR}$ spectra of compound 4, Figure S16: ${ }^{1} \mathrm{H}-\mathrm{NMR}$ spectra of compound 5, Figure S17: ${ }^{13} \mathrm{C}-\mathrm{NMR}$ spectra of compound 5, Figure S18: ${ }^{1} \mathrm{H}-\mathrm{NMR}$ spectra of compound 6, Figure S19: ${ }^{13} \mathrm{C}-\mathrm{NMR}$ spectra of compound 6 .

Author Contributions: Conceptualization, L.W. and G.C.; methodology, L.W. and G.C.; investigation, N.W., J.Z., G.W., and W.C.; formal analysis, P.L. and Z.Z.; writing—original draft preparation, N.W. All authors have read and agreed to the published version of the manuscript.

Funding: This work was supported by the National Natural Science Foundation of China (grant number 81502944) and the Innovation Project of Guangdong Graduate Education (grant number 2020SFKC047).

Institutional Review Board Statement: Not applicable.

Informed Consent Statement: Not applicable.

Data Availability Statement: The data presented in this study are available on request from the corresponding author.

Conflicts of Interest: The authors declare no conflict of interest.

Sample Availability: Samples of the compounds are not available from the authors.

\section{References}

1. Chinen, A.B.; Guan, C.M.; Ferrer, J.R.; Barnaby, S.N.; Merkel, T.J.; Mirkin, C.A. Nanoparticle probes for the detection of cancer biomarkers, cells, and tissues by fluorescence. Chem. Rev. 2015, 115, 10530-10574.

2. Sun, M.; Xu, L.; Ma, W.; Wu, X.; Kuang, H.; Wang, L.; Xu, C. Hierarchical plasmonic nanorods and upconversion core-satellite nanoassemblies for multimodal imaging-guided combination phototherapy. Adv. Mater. 2016, 28, 898-904. [CrossRef]

3. Rosenblum, D.; Gutkin, A.; Kedmi, R.; Ramishetti, S.; Veiga, N.; Jacobi, A.M.; Schubert, M.S.; Friedmann-Morvinski, D.; Cohen, Z.R.; Behlke, M.A.; et al. CRISPR-Cas9 genome editing using targeted lipid nanoparticles for cancer therapy. Sci. Adv. 2020, 6, eabc9450.

4. Srinivasan, S.Y.; Gajbhiye, V.; Bodas, D. Development of nano-immunosensor with magnetic separation and electrical detection of Escherichia coli using antibody conjugated $\mathrm{Fe}_{3} \mathrm{O}_{4} @$ Ppy. Nanotechnology 2021, 32, 085603. [PubMed]

5. Zhu, Y.T.; Ren, X.Y.; Yuan, L.; Liu, Y.M.; Liang, J.; Liao, X. Fast identification of lipase inhibitors in oolong tea by using lipase functionalised $\mathrm{Fe}_{3} \mathrm{O}_{4}$ magnetic nanoparticles coupled with UPLC-MS/MS. Food Chem. 2015, 173, 521-526. [CrossRef]

6. Van Durme, R.; Crevecoeur, G.; Dupré, L.; Coene, A. Model-based optimized steering and focusing of local magnetic particle concentrations for targeted drug delivery. Drug Deliv. 2021, 28, 63-76. 
7. Kokolus, K.M.; Haley, J.S.; Koubek, E.J.; Gowda, R.; Dinavahi, S.S.; Sharma, A.; Claxton, D.F.; Helm, K.F.; Drabick, J.J.; Robertson, G.P.; et al. Schweinfurthin natural products induce regression of murine melanoma and pair with anti-PD-1 therapy to facilitate durable tumor immunity. Oncoimmunology 2018, 8, e1539614. [CrossRef] [PubMed]

8. Li, Y.; Chen, Y.; Xiao, C.; Chen, D.; Xiao, Y.; Mei, Z. Rapid screening and identification of $\alpha$-amylase inhibitors from Garcinia xanthochymus using enzyme-immobilized magnetic nanoparticles coupled with HPLC and MS. J. Chromatogr. B Analyt. Technol. Biomed. Life Sci. 2014, 960, 166-173.

9. Peng, M.; Zhang, Y.; Shi, S.; Peng, S. Simultaneous ligand fishing and identification of human serum albumin binders from Eucommia ulmoides bark using surface plasmon resonance-high performance liquid chromatography-tandem mass spectrometry. J. Chromatogr. B Analyt. Technol. Biomed. Life Sci. 2013, 940, 86-93.

10. Sun, L.; Li, Y.; Yang, P.; Zhu, G.; Dovichi, N.J. High efficiency and quantitatively reproducible protein digestion by trypsinimmobilized magnetic microspheres. J. Chromatogr. A 2012, 1220, 68-74. [PubMed]

11. Wu, G.F.; Jiang, X.L.; Gong, Y.Z.; Hu, Y.D.; Bai, X.L.; Liao, X. Ligand fishing of anti-neurodegenerative components from Lonicera japonica using magnetic nanoparticles immobilised with monoamine oxidase B. J. Sep. Sci. 2019, 42, 1289-1298. [CrossRef]

12. Shen, Y.; Wang, M.; Zhou, J.; Chen, Y.; Wu, M.; Yang, Z.; Yang, C.; Xia, G.; Tam, J.P.; Zhou, C.; et al. Construction of Fe ${ }_{3} \mathrm{O}_{4} @ \alpha-$ glucosidase magnetic nanoparticles for ligand fishing of $\alpha$-glucosidase inhibitors from a natural tonic Epimedii Folium. Int. J. Biol. Macromol. 2020, 165 Pt A, 1361-1372. [CrossRef]

13. Zuo, J.; Tong, L.; Du, L.; Yang, M.; Jin, Y. Biomimetic nanoassemblies of 1-O-octodecyl-2-conjugated linoleoyl-sn-glycero-3phosphatidyl gemcitabine with phospholipase $\mathrm{A}_{2}$-triggered degradation for the treatment of cancer. Colloids. Surf. B Biointerfaces 2017, 152, 467-474. [CrossRef]

14. Bennett, D.T.; Deng, X.S.; Yu, J.A.; Bell, M.T.; Mauchley, D.C.; Meng, X.; Reece, T.B.; Fullerton, D.A.; Weyant, M.J. Cancer stem cell phenotype is supported by secretory phospholipase $\mathrm{A}_{2}$ in human lung cancer cells. Ann. Thorac. Surg. 2014, 98, 439-445. [CrossRef] [PubMed]

15. Jiang, J.; Neubauer, B.L.; Graff, J.R.; Chedid, M.; Thomas, J.E.; Roehm, N.W.; Zhang, S.; Eckert, G.J.; Koch, M.O.; Eble, J.N.; et al. Expression of group IIA secretory phospholipase $\mathrm{A}_{2}$ is elevated in prostatic intraepithelial neoplasia and adenocarcinoma. Am. J. Pathol. 2002, 160, 667-671. [CrossRef]

16. Yamashita, S.; Yamashita, J.; Ogawa, M. Overexpression of group II phospholipase $\mathrm{A}_{2}$ in human breast cancer tissues is closely associated with their malignant potency. Br. J. Cancer 1994, 69, 1166-1170. [CrossRef] [PubMed]

17. Shibata, K.; Nishimura, J.; Yufu, Y.; Nawata, H. Alterations in thrombin-induced protein tyrosine phosphorylation of platelets from patients with chronic myelogenous leukemia. Int. J. Hematol. 1992, 55, 189-196.

18. Murakami, M. Novel functions of phospholipase $\mathrm{A}_{2}$ s: Overview. Biochim. Biophys. Acta Mol. Cell Biol. Lipids 2019, 1864, 763-765. [CrossRef]

19. Cummings, B.S. Phospholipase $\mathrm{A}_{2}$ as targets for anti-cancer drugs. Biochem. Pharmacol. 2007, 74, 949-959. [CrossRef]

20. Cai, R.; Wu, Y.; Chen, S.; Cui, H.; Liu, Z.; Li, C.; She, Z. Peniisocoumarins A-J: Isocoumarins from Penicillium commune QQF-3, an endophytic fungus of the mangrove plant Kandelia candel. J. Nat. Prod. 2018, 81, 1376-1383. [CrossRef]

21. Deshmukh, S.K.; Gupta, M.K.; Prakash, V.; Reddy, M.S. Mangrove-associated fungi: A novel source of potential anticancer compounds. J. Fungi 2018, 4, 101. [CrossRef] [PubMed]

22. Li, W.; Jan, Z.; Ding, Y.; Liu, Y.; Janko, C.; Pischetsrieder, M.; Alexiou, C.; Boccaccini, A.R. Facile preparation of multifunctional superparamagnetic PHBV microspheres containing SPIONs for biomedical applications. Sci. Rep. 2016, 6, 23140. [CrossRef] [PubMed]

23. Amin, F.U.; Shah, S.A.; Badshah, H.; Khan, M.; Kim, M.O. Anthocyanins encapsulated by PLGA@PEG nanoparticles potentially improved its free radical scavenging capabilities via p38/JNK pathway against A $\beta 1-42$-induced oxidative stress. J. Nanobiotechnol. 2017, 15, 12. [CrossRef] [PubMed]

24. Homaei, A.A.; Sariri, R.; Vianello, F.; Stevanato, R. Enzyme immobilization: An update. J. Chem. Biol. 2013, 6, 185-205. [CrossRef]

25. Chen, X.; Mou, Y.; Ling, J.; Wang, N.; Wang, X.; Hu, J. Cyclic dipeptides produced by fungus Eupenicillium brefeldianum HMP-F96 induced extracellular alkalinization and $\mathrm{H} 2 \mathrm{O} 2$ production in tobacco cell suspensions. World J. Microbiol. Biotechnol. 2015, 31, 247-253. [CrossRef]

26. Furtado, N.A.J.C.; Pupo, M.T.; Carvalho, I.; Campo, V.L.; Duarte, M.C.T.; Bastos, J.K. Diketopiperazines produced by an Aspergillus fumigatus Brazilian strain. J. Braz. Chem. Soc. 2005, 16, 1448-1453. [CrossRef]

27. MacIntyre, L.W.; Marchbank, D.H.; Correa, H.; Kerr, R.G. Fusaristatin C, a cyclic lipodepsipeptide from Pithomyces sp. RKDO 1698. J. Nat. Prod. 2018, 81, 2768-2772. [CrossRef]

28. Yu, L.; Mei, W.L.; Zuo, W.J.; Wang, H.; Guo, Z.K.; An, X.Q.; Dai, H.F. Antimicrobial constituents from the twigs of Trigonostemon xyphophylloides. Lishizhen Med. Mater. Med. Res. 2013, 24, 591-593.

29. Li, J.T.; Chen, Q.Q.; Zeng, Y.; Wang, Q.; Zhao, P.J. A new phenol compound from endophytic Phomopsis sp. DC01. Nat. Prod. Res. 2012, 26, 2008-2012. [CrossRef]

30. Munkhgerel, L.; Luo, G.Y.; Zhou, M.; Regdel, D.; Zhang, G.L.; Luo, Y.G. Chemical components from an edible mushroom Agaricus silvaticus. Chin. J. Appl. Environ. Biol. 2014, 20, 629-632.

31. Sun, Y.W.; Li, C.W.; Cui, C.B.; Yao, Z.W. Metabolites newly produced by a streptomycin-resistant antitumor mutant obtained from a marine-derived wild-type actinomycete strain without antitumor activity. Bull. Acad. Milit. Med. Sci. 2010, 34, 119-122. 
32. Li, D.H.; Gu, Q.Q.; Zhu, W.M.; Liu, H.B.; Fang, Y.C.; Zhu, T.J. Antitumor components from marine actinomycete 11014 I.Cyclic dipeptides. Chin. J. Antibio. 2005, 8, 449-452+468.

33. Liu, H.B.; Gao, H.; Wang, N.L.; Lin, H.P.; Hong, K.; Yao, X.S. Cyclic dipeptide constituents from the mangrove fungus Penicillium oxalicum (No. 092007). J. Shenyang Pharm. Univ. 2007, 24, 474-478.

34. Tang, Q.J.; Wang, J.Y.; Wang, Y.T.; Liu, Y.F.; Feng, N.; Zhang, J.S. Isolation, Purification and Activity Study of Active Components in Ganoderma Lucidum Spore Powder. In Proceedings of the 2018 Annual Meeting of Mycological Society of China, Taian, China, 11 August 2018.

35. Meza-Menchaca, T.; Poblete-Naredo, I.; Albores-Medina, A.; Pedraza-Chaverri, J.; Quiroz-Figueroa, F.R.; Cruz-Gregorio, A.; Zepeda, R.C.; Melgar-Lalanne, G.; Lagunes, I.; Trigos, Á. Ergosterol Peroxide Isolated from Oyster Medicinal Mushroom, Pleurotus ostreatus (Agaricomycetes), Potentially Induces Radiosensitivity in Cervical Cancer. Int. J. Med. Mushrooms. 2020, 22, 1109-1119. [CrossRef] [PubMed]

36. Hao, J.F. Identification and Evaluation of Bioactivity of Small Molecule Functional Components from the Mushroom Pleurotus nebrodensis. Master's Thesis, Tianjin University, Tianjin, China, 2017.

37. El-Gogary, R.I.; Rubio, N.; Wang, J.T.; Al-Jamal, W.T.; Bourgognon, M.; Kafa, H.; Naeem, M.; Klippstein, R.; Abbate, V.; Leroux, F.; et al. Polyethylene glycol conjugated polymeric nanocapsules for targeted delivery of quercetin to folate-expressing cancer cells in vitro and in vivo. ACS Nano 2014, 8, 1384-1401. [CrossRef]

38. Aggarwal, S.; Gupta, S.; Pabla, D.; Murthy, R.S. Gemcitabine-loaded PLGA-PEG immunonanoparticles for targeted chemotherapy of pancreatic cancer. Cancer Nanotechnol. 2013, 4, 145-157. [CrossRef] [PubMed]

39. Zhang, N.; Chittasupho, C.; Duangrat, C.; Siahaan, T.J.; Berkland, C. PLGA nanoparticle-peptide conjugate effectively targets intercellular cell-adhesion molecule-1. Bioconjug. Chem. 2008, 19, 145-152. [CrossRef]

40. Esmaeili, F.; Ghahremani, M.H.; Ostad, S.N.; Atyabi, F.; Seyedabadi, M.; Malekshahi, M.R.; Amini, M.; Dinarvand, R. Folatereceptor-targeted delivery of docetaxel nanoparticles prepared by PLGA-PEG-folate conjugate. J. Drug Target. 2008, 16, 415-423. [CrossRef]

41. Yoo, H.S.; Park, T.G. Folate receptor targeted biodegradable polymeric doxorubicin micelles. J. Control. Release 2004, 96, 273-283. [CrossRef]

42. Mhlanga, N.; Sinha Ray, S.; Lemmer, Y.; Wesley-Smith, J. Polylactide-based magnetic spheres as efficient carriers for anticancer drug delivery. ACS Appl. Mater. Interfaces 2015, 7, 22692-22701. [CrossRef]

43. Verma, N.K.; Crosbie-Staunton, K.; Satti, A.; Gallagher, S.; Ryan, K.B.; Doody, T.; McAtamney, C.; MacLoughlin, R.; Galvin, P.; Burke, C.S.; et al. Magnetic core-shell nanoparticles for drug delivery by nebulization. J. Nanobiotechnol. 2013, 11, 1-12. [CrossRef] [PubMed] 